\title{
Notes on the genus Psychostrophia Butler, 1877 (Lepidoptera, Epicopeiidae), with description of a new species
}

\author{
Si-Yao Huang', Min Wang', Xiao-Ling Fan' \\ I Department of Entomology, College of Agriculture, South China Agricultural University, Guangzhou510642, \\ Guangdong, China \\ Corresponding author: Xiao-Ling Fan (fanxiaol66@scau.edu.cn)
}

Academic editor: A. Hausmann | Received 1 October 2019 | Accepted 3 December 2019 | Published 31 December 2019

http://zoobank.org/23EA5A19-B3BE-403F-AA45-E0EE56E98C8C

Citation: Huang S-Y, Wang M, Fan X-L (2019) Notes on the genus Psychostrophia Butler, 1877 (Lepidoptera, Epicopeiidae), with description of a new species. ZooKeys 900: 111-127. https://doi.org/10.3897/zookeys.900.46973

\begin{abstract}
New information on the genus Psychostrophia Butler, 1877 is provided. A new species, Psychostrophia micronymphidiaria Huang \& Wang, sp. nov., is described from western, northern and northwestern Yunnan Province, southwestern China; it is similar to P. nymphidiaria (Oberthür, 1893) which is widely distributed in eastern, southern, western and central China. A new synonym is established: Psychostrophia nymphidiaria (Oberthür, 1893) (= Stiboges lushanica Chou \& Yuan, 2001, syn. nov.). Some other taxonomic and nomenclatural notes on the genus are presented. A key to the species of the genus Psychostrophia is provided.
\end{abstract}

\section{Keywords}

cryptic species, East Asia, Geometroidea, oriental swallowtail moth, taxonomy

\section{Introduction}

Psychostrophia Butler, 1877 is a small genus belonging to the family Epicopeiidae, which is widely distributed across Japan, China, and Indochina (Inoue 1992; Zhu et al. 2004; Owada 2011). This genus is characterized by the following characters: 1) hindwing with cilia mostly black, except for a white area between veins M1 and M3; 
2) uncus long, thin, and tubular for most of its length; and 3) aedeagus with a cluster of slender cornuti, and coecum well developed and long (Minet 2003; Huang et al. 2019). Adults are diurnal, delicate moths, usually found flying along the forest edge or near water, visiting flowers or sucking nutrients from the damp ground. The immature stage is unknown for most of the members, and only the Japanese P. melanargia is found to feed on Clethra barbinervis of the family Clethraceae (Inoue 1982; Owada 2011). Until now only four species are known in this genus, viz. P. melanargia Butler, 1877, P. nymphidiaria (Oberthür, 1893), P. picaria Leech, 1897, and P. endoi Inoue, 1992, all of which have been previously recorded from China (Zhu et al. 2004; Huang et al. 2019).

Thus far, this genus has only been represented by $P$. endoi in Deqin County in Yunnan Province (Huang et al. 2019). The first observation of another member was of a worn-out male of a Psychostrophia species with a P. nymphidiaria-like appearance, flying together with another epicopeiid, Burmeia leesi Minet, 2003, at the edge of an evergreen broad-leaved forest near water at an altitude around $2550 \mathrm{~m}$. This unexpected recording by the authors took place during a field survey conducted in Yaojiaping, Lushui County, on the western slope of the Gaoligong Mountains in western Yunnan province in the summer of 2018. Subsequently, the first author discovered in the Lepidoptera collection of the South China Agricultural University several males of this $P$. nymphidiaria-like species, which were collected from a vast area in Yunnan. Although at first glance they showed a striking similarity to P. nymphidiaria from other parts of China, some small but distinctive morphological differences were noticed. After examining the genitalia, these individuals were found to have distinguishing genital features, confirming them to represent a species distinct from the true P. nymphidiaria, making it the fifth species of the genus Psychostrophia Butler, 1877. It is described herein.

During the course of studying the genus Psychostrophia, the taxon Stiboges lushanica Chou \& Yuan, 2001, originally described as a new butterfly, was found to be synonymous with $P$. nymphidiaria (Oberthür, 1893). Two names, $P$. melanargia ab. hemimelaena Seitz, 1912 and P. melanargia ab. catenifer Seitz, 1912 are unavailable as infrasubspecific, even after Zhu et al. (2004) provided a description of $P$. melanargia ab. hemimelaena. All the synonymic relationships and unavailable names mentioned above are discussed in detail below.

\section{Material and methods}

Specimens examined in this study were all collected in daytime using an insect net and subsequently deposited in the collection of South China Agricultural University (SCAU), Guangzhou. The photographs of the holotype of S. lushanica in the collection of Northwest Agriculture and Forestry University (NWAFU) were provided courtesy of Dr Guo-xi Xue and used here under permission of Dr Xiangqun Yuan. Photographs of all adult specimens examined were taken using a Nikon CoolPix S7000 camera and the habitat photographs with a Sony DSC-RX100 v1.00 camera. Abdomens were 
removed and macerated in $10 \% \mathrm{NaOH}$ for examination of genitalia. Photographs of genitalia of Psychostrophia spp. were taken under a Keyence VHX-5000 digital microscope. Adult and genitalia photographs were all processed using Adobe Photoshop CS5 software. Terminology for adults and genitalia follows Klots (1970) and Minet (2003). The specimen code for linking adult and genitalia together is numbered from PSY001 to PSY017.

\section{Taxonomy}

Genus Psychostrophia Butler, 1877

Psychostrophia Butler 1877: 401.

Type species. Psychostrophia melanargia Butler, 1877 (Yokohama, Japan).

\section{Psychostrophia micronymphidiaria Huang \& Wang, sp. nov.} http://zoobank.org/AF2ECA37-9EE3-4EDD-A074-5BA0766976E6 Figs 1-4, 9, 10

Psychostrophia nymphidiaria: Huang et al. 2019: 40 [misidentification].

Type material. Holotype: male, altitude 2779-2927 m, 27.V.2016, near Shajiama Bridge, Tacheng Town, Weixi Lisu Autonomous County, Diqing Tibetan Autonomous Prefecture, Yunnan Province, leg. Zhen-fu Huang, Qi-tong Huang and Jing Tang, PSY001. Paratypes: 1 male, same label as holotype, PSY002; 1 male, altitude $2550 \mathrm{~m}$, 15.VII.2018, Yaojiaping, Lushui County, Nujiang Lisu Autonomous Prefecture, Yunnan Province, PR China, leg. Si-yao Huang, PSY003; 1 male, 6.VII.2014, altitude 2900-3000 m, Mt Diancang, Dali Bai Autonomous Prefecture, Yunnan Province, leg. Hao Huang, PSY004; 1 male, altitude 2850 m, 7.VII.2013, Tacheng Town, Weixi Lisu Autonomous County, Diqing Tibetan Autonomous Prefecture, Yunnan Province, leg. Zhen-fu Huang, Hai-ling Zhuang and Min Wang, PSY005. The type series is deposited in the Insect Collection of Department of Entomology, South China Agricultural University (SCAU), Guangzhou, P. R. China.

Diagnosis. Externally, P. micronymphidiaria sp. nov. is characterized and distinguished from its closest relative, P. nymphidiaria by a smaller size (length of forewing $16-17 \mathrm{~mm}$ vs $18-22 \mathrm{~mm}$ in P. nymphidiaria), more slender discal cell bar with the tip pointing to the tornus (in P. nymphidiaria the discal cell bar is robust and short, the tip shifting basally and pointing to the dorsum), and a narrower costal black border on the dorsal forewing. The male genitalia of $P$. micronymphidiaria sp. nov. can be distinguished from those of $P$. nymphidiaria by the following points: 1 ) the juxta is much narrower and more strongly sclerotized, while it is much broader and more membra- 


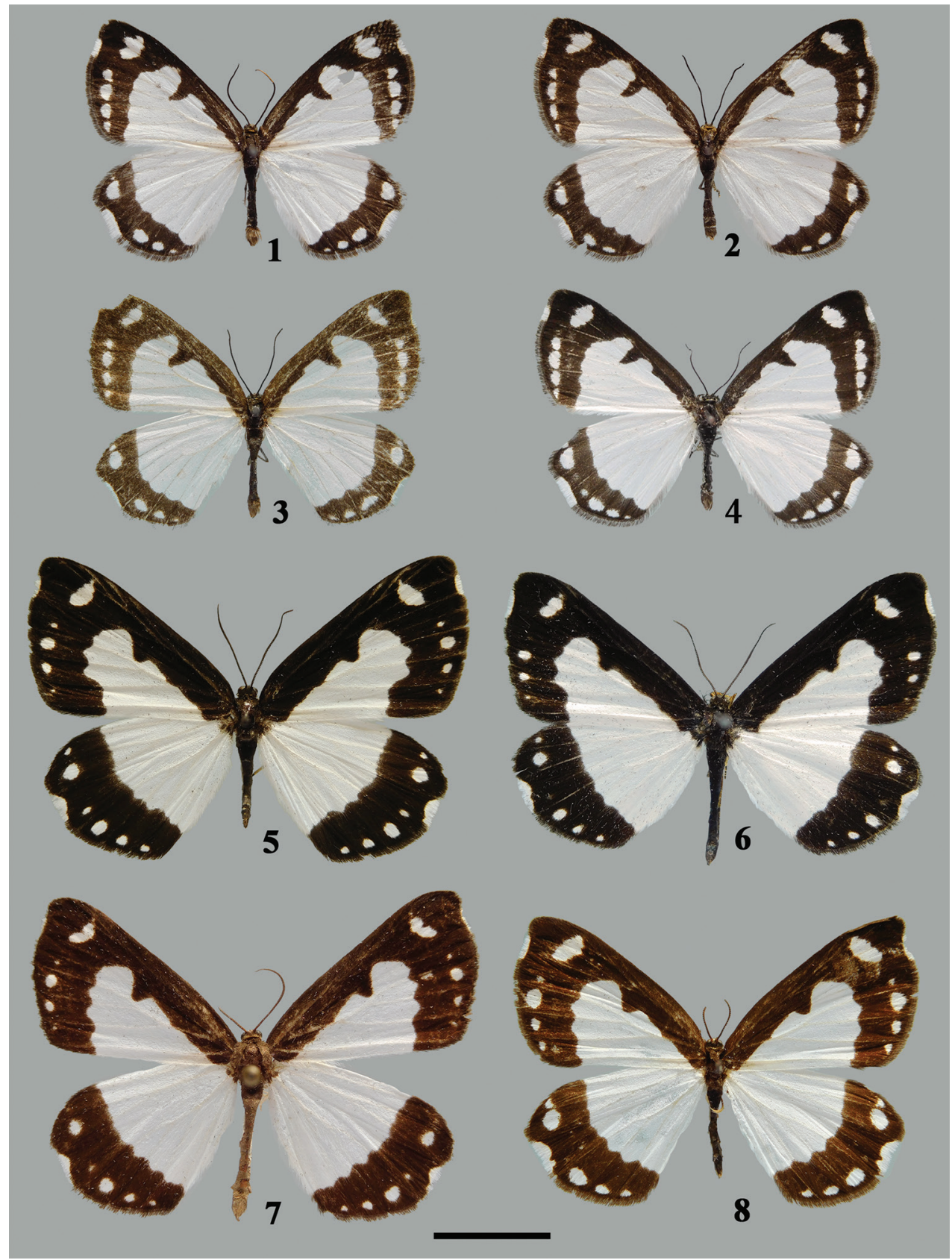

Figures I-8. Males of Psychostrophia spp. I Psychostrophia micronymphidiaria sp. nov., holotype, Weixi, Yunnan, PSY001 2 ditto, paratype, Weixi, Yunnan, PSY002 3 ditto, paratype, Lushui, Yunnan, PSY003 4 ditto, paratype, Dali, Yunnan, PSY004 5 Psychostrophia nymphidiaria, Jiangshan, Zhejiang, PSY006 6 ditto, Qingyuan, Zhejiang, PSY008 7 ditto, Nanling, Guangdong, PSY009 8 ditto, Yingjing, Sichuan, PSY007. Scale bar: $1 \mathrm{~cm}$. 
nous in $P$. nymphidiaria; 2 ) the valva has a narrower praesacculus, while it is broader in P. nymphidiaria; 3) the aedeagus is longer than the coecum, while it is shorter than the coecum or equal to it in P. nymphidiaria; 4) coecum and aedeagus are more sclerotized, while they are more membranous in P. nymphidiaria.

Description. Male (Figs 1-4). Forewing length 16-17 mm $(n=5)$. Head black; antenna black, filiform. Thorax and abdomen black dorsally. Forewing ground color black with well-developed white patterns. White triangular zone extending from wing base to postmedial area, ending in wavy edge; cell bar at end of discal cell slender; subapical area with oval white patch, center sometimes extending outwards. Submarginal series comprising four white spots extending from vein $\mathrm{M}_{2}$ to anal angle. Cilia black from apex to vein $R_{5}$, white from $R_{5}$ to middle portion of cell $M_{1}$, becoming black again from medial portion of cell $M_{1}$ to tornus; sometimes cilia white only between vein $R_{5}$ and vein $M_{1}$. Dorsally, hindwing ground color white at inner two-thirds and black at outer one-third, junction line between white and black area wavy; submarginal series consisting of four to six white spots of different sizes, extending from apex to tornus; cilia black from apex to vein $M_{1}$, white from $M_{1}$ to medial portion of cell $M_{2}$, becoming black again from medial portion of cell $\mathrm{M}_{2}$ to tornus.

Male genitalia (Figs 9, 10). Uncus tubular, relatively long, and slender. Tegumen broadly U-shaped in ventral view, rather short and broad. Subscaphium moderately sclerotized, bearing setae in ventral and distal areas. Costula at base of costa, consisting of two sclerotized, crescent-shaped processes connected by a membrane. Juxta small and shield-like, strongly sclerotized. Saccus sclerotized, short and diamond-shaped. Valva shape varies from broad and stout to relatively slender, inner surface densely setose. Costa strongly sclerotized. Sacculus strongly sclerotized, broadened basally, narrowing distally. Praesacculus strongly sclerotized and bending upwards, ending with long and sharp tip. Aedeagus long and slender, sclerotized, cluster of long and thin cornuti present distally. Coecum strongly sclerotized, slightly shorter than aedeagus.

Female. Unknown at present.

Distribution. This species is currently known to occur in western, northern and northwestern Yunnan province of China (Fig. 25).

Etymology. The specific name micronymphidiaria is the combination of prefix $m i$ cro- and nymphidiaria, referring to the size of the new species, which is smaller than $P$. nymphidiaria.

Bionomics. This species has been found to fly at the periphery of evergreen broadleaf forests or conifer-broadleaf forests near water, at altitudes above $2500 \mathrm{~m}$ (Figs 21, 22) from late May to mid July. Adults are diurnal and commonly found flying at a slow pace above bushes.

Remarks. At present this species is restricted to habitats at altitudes above $2500 \mathrm{~m}$ in the Yunnan Province of southwestern China. Conversely, P. nymphidiaria is distributed across a vast area ranging from Sichuan Province to Zhejiang Province and extending southwards to northern Guangdong Province, typically preferring habitats where the altitude does not exceed $2200 \mathrm{~m}$ (usually from 300 to $2000 \mathrm{~m}$ ). 


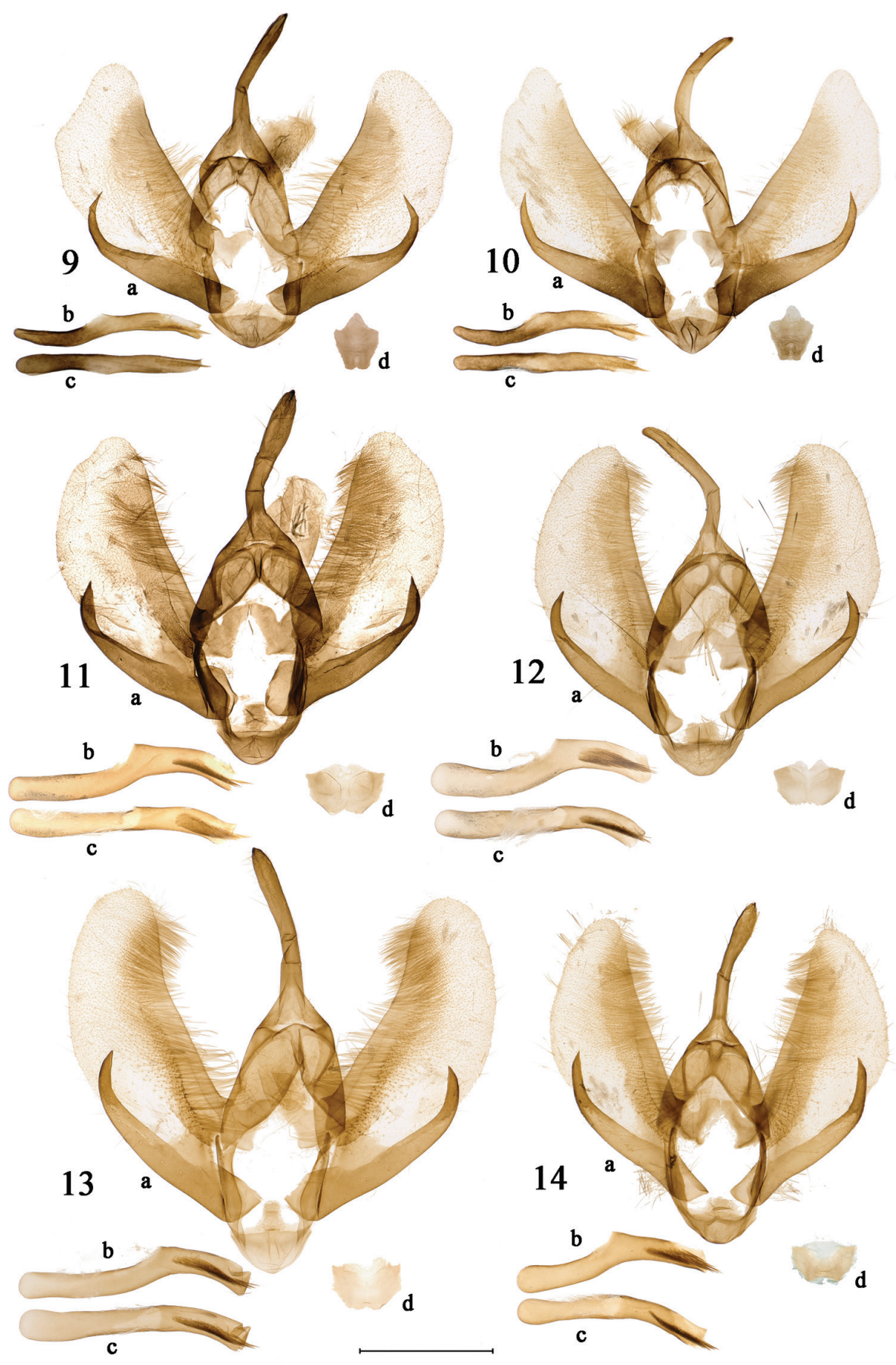

Figures 9-14. Male genitalia of Psychostrophia spp. 9 Psychostrophia micronymphidiaria sp. nov., holotype, Weixi, Yunnan, PSY001 10 ditto, paratype, Weixi, Yunnan, PSY002 II Psychostrophia nymphidiaria, Jiangshan, Zhejiang, PSY006 I 2 ditto, Qingyuan, Zhejiang, PSY008 I 3 ditto, Nanling, Guangdong, PSY009 $\mathbf{1}$ ditto, Yingjing, Sichuan, PSY007. $\mathbf{a}=$ male genitalia capsule with juxta removed; $\mathbf{b}=$ aedeagus lateral view; $\mathbf{c}=$ aedeagus dorsal view; $\mathbf{d}=$ juxta. Scale bar: $1 \mathrm{~mm}$. 


\section{Psychostrophia nymphidiaria (Oberthür, 1893)}

Figs 5-8, 11-15

Abraxas nymphidiaria Oberthür 1893: 34, pl. 2, fig. 28. [Type locality: "Rencontrée pendant le voyage de Ta-Tsien-Lou à Mou-Pin” (Road from Kangding to Baoxing)]. Psychostrophia nymphidiaria (Oberthür): Leech 1897: 189; Seitz 1912: 278; Minet 2003: 473, 479, fig. 4.

Stiboges lushanica Chou and Yuan 2001: 142, fig. 15, 16. syn. nov. (Riodinidae).

Material examined. Photos of holotype of Stiboges lushanica, male, printed label in Chinese "[Sichuan, Lushan, leg. Bing-hong Wang]"/ printed red label "Holotype" / red label "Stiboges lushanica Chou et etc., IDENT. IO CHOU" (NWAFU); 1 male, 22.VI.2003, Nanling Mts, Guangdong Province, leg. Min Wang, PSY009 (SCAU); 1 female, 2.VIII.2003, Huanjiang Maonan Autonomous County, Guangxi Zhuang Autonomous Prefecture, leg. Min Wang (SCAU); 1 male, 10.V.2018, Luding County, Sichuan Province, leg. Min Wang (SCAU); 1 male, altitude 1700-1900 m, 13.VI.2012, Mt Niba, Yingjing County, Ya’an City, Sichuan Province, leg. Xiao-hua Deng \& Hou-shuai Wang, PSY007 (SCAU); 1 male, 11.VIII.2016, Shuangxikou Town, Jinyun County, Jiangshan City, Zhejiang Province, leg. Shu-qin Ji \& Hou-shuai Wang, PSY006 (SCAU); 1 male, 25.VII-15.VIII.2018, Qingyuan County, Lishui City, Zhejiang Province, leg. Qing-song Wu, PSY008 (SCAU); 1 male, altitude $1500 \mathrm{~m}$, 3. VI. 2019, Guanmenshan, Shennongjia, Yichang City, Hubei Province (SCAU); 2 males, 21.V.2011, Huanggangshan, Mt Wuyi, Fujian Province, leg. Zhen-fu Huang \& Qi-tong Huang (SCAU); 2 males, altitude 1300 m, 13.VIII.2014, Mt Tianping, Zhangjiajie City, Hunan Province, leg. Lan-lan Huang, Wan Lu, Qi-tong Huang \& Min Wang (SCAU).

Remarks. Taxon Stiboges lushanica Chou \& Yuan, 2001 was described based on two specimens taken in Lushan County, Ya'an City in western Sichuan Province. Kishida (2006) was first to point out that this "butterfly" taxon is conspecific with P. nymphidiaria, but did not synonymize it formally. With the help of Dr Guo-xi Xue and the permission from Dr Xiangqun Yuan, the photographs of the holotype could be examined. The holotype is a male of the oriental swallowtail moth species P. nymphidiaria. Although the male genitalia were not illustrated, the description by Chou and Yuan (2001) as well as the photographs suggest that these individuals are undoubtedly conspecific with this epicopeiid moth species commonly found in that area, rather than a bona species of the riodinid butterfly genus Stiboges Butler, 1876. Although their mimicry relationship makes them morphologically similar, one can easily recognize this moth species simply by the filiform antenna. Thus, S. lushanica is considered a junior synonym of $P$. nymphidiaria (syn. nov.).

Nevertheless, according to Dr Guo-xi Xue and Dr Xiangqun Yuan, there is another specimen also bearing the holotype red label of S. lushanica in the collection of NWAFU, and this specimen is illustrated here for the first time (Fig. 16). The information on the labels is interpreted as follows: "[Sichuan, Lushan, leg. Jing-hua Wang]"/ printed red label “Holotype” / red label “芦山白蚬蝶, Stiboges lushanica Chou et Yuan, IDENT. IO 


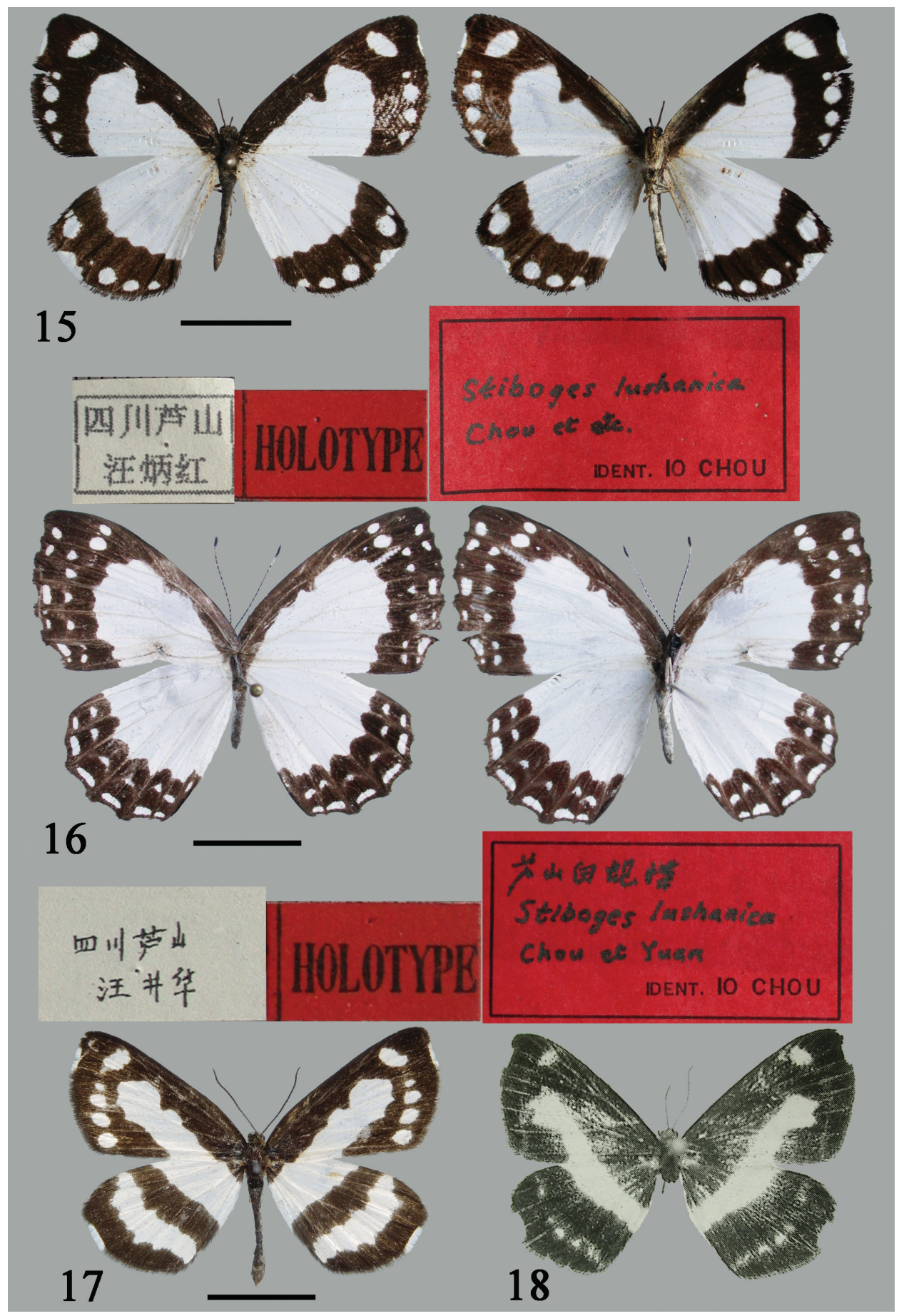

Figures I5-1 8. Adults of Psychostrophia spp. and Stiboges sp. 15, I 7-18 male $\mathbf{1 6}$ female: 15 Psychostrophia nymphidiaria, holotype of Stiboges lushanica, Lushan, Sichuan 16 Stiboges elodinia, mislabeled specimen of "holotype" of Stiboges lushanica, Lushan, Sichuan $\mathbf{7}$ Psychostrophia picaria, Shennongjia, Hubei, PSY017 $I 8$ holotype of Psychostrophia endoi, Xam Neua, Laos, from Inoue (1992). Scale bars: $1 \mathrm{~cm}$. 
CHOU". This specimen is a female of Stiboges elodinia Fruhstorfer, 1914 in the opinion of Callaghan (2009). Chou and Yuan (2001) stated in English that the sex of the holotype of S. lushanica was female, which would suggest that this taxon is a true butterfly. However, the descriptions in both Chinese and English have all clearly expressed that the holotype is conspecific with the male of P. nymphidiaria and definitely not a female riodinid butterfly. According to Article 73.1.1 of the Code (ICZN 1999), if an author, when establishing a new nominal species-group taxon, states in the original publication that one specimen, and only one, is the holotype, or "the type", or uses some equivalent expression, that specimen is the holotype fixed by original designation. The specimen of P. nymphidiaria pictured in figure 16 of Chou and Yuan (2001) was fixed as the holotype of $S$. lushanica since the word "holotype" was plainly used in Chinese in the legend under this figure. The holotype status of that female riodinid butterfly, which was subsequently labeled as the holotype of $S$. lushanica, is therefore invalid, making the true holotype of this taxon the specimen of P. nymphidiaria shown in figure 16 of Chou and Yuan (2001).

During the study of the populations of $P$. nymphidiaria from various localities, it was found that males vary externally and in their genitalia. The median white zone on the dorsal forewing varies in shape and size, and the genitalia vary in the shape of the valva, length and width of the praesacculus, and the ratio of the aedeagus to the coecum (Figs 5-8, 11-14). It is possible that cryptic species still exist within P. nymphidiaria sensu lato, a possibility that deserves a more careful investigation including the examination of more adults and genitalia of both sexes, as well as conducting DNA barcoding in the future.

Distribution. China (Sichuan, Hubei, Hunan, Zhejiang, Fujian, Guangdong, Guangxi Zhuang Autonomous Region) (Fig. 25)

\section{Psychostrophia picaria Leech, 1897}

Figs 17, 19

Psychostrophia picaria Leech 1897: 189, pl. VI, fig. 11. [Type locality: Changyang, Ichang (now Yichang), Central China]; Seitz 1912: 278; Minet 2003: 473, 478, fig. 5, 24 .

Material examined. 1 male, altitude 1000-1400 m, 13.V.2015, Muyu Town, Shennongjia, Yichang City, Hubei Province, leg. Yu-fei Li, PSY017 (SCAU); 1 female, 11-14.V.2007, Mt Tianping, Zhangjiajie City, Hunan Province, leg. Liu-sheng Chen, Zhen Li \& Yang Long (SCAU); 3 males, 9.VII.2015, Mt Simian, Chongqing City, leg. Si-yao Huang (SCAU); 1 male, 1 female, 1.VII.2003, Mt Maoer, Guangxi Zhuang Autonomous Region, leg. Min Wang (SCAU).

Remarks. Huang et al. (2019) stated that the difference in male genitalia between $P$. endoi and $P$. picaria lies in the shape of the valva, which protrudes more at the apex in $P$. endoi. However, the more protruding valva apex is actually found in P. picaria. The photographs of adult and male genitalia of a $P$. picaria collected in Shennongjia, Yichang, Hubei Province have been illustrated here for comparison. Judging from the structures of the male genitalia, both the sacculus and praesacculus of P. picaria are 


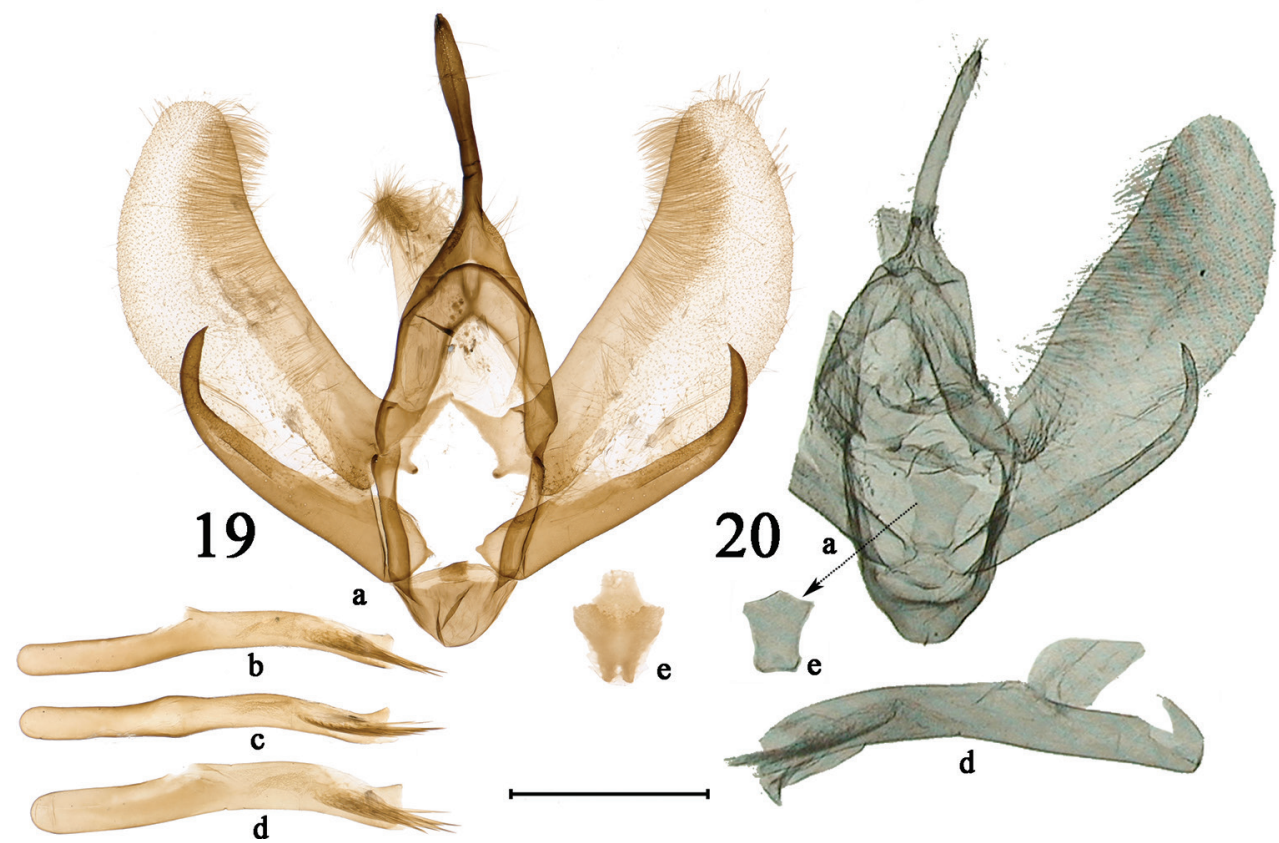

Figures 19, 20. Male genitalia of Psychostrophia spp. 19 Psychostrophia picaria, Shennongia, Hubei, PSY017 20 holotype of Psychostrophia endoi, Xam Neua, Laos, from Inoue (1992). a = male genitalia capsule with juxta removed; $\mathbf{b}=$ aedeagus lateral view; $\mathbf{c}=$ aedeagus dorsal view; $\mathbf{d}=$ flattened aedeagus in lateral view; e = juxta. Scale bar: $1 \mathrm{~mm}$ (19).

thicker than those of $P$. endoi, and the upper lobe of the juxta is much broader and longer than that of $P$. endoi. However, given that the valva structure is variable in $P$. nymphidiaria, it is possible that the differences in valva structure mentioned above between these two species are still not constant. Thus, only the shape of the juxta can currently be regarded as a true distinguishing characteristic. More material of male $P$. endoi should be examined to confirm such differences.

Distribution. China (Hubei, Hunan, Chongqing, Guangxi Zhuang Autonomous Region) (Fig. 25).

\section{Psychostrophia endoi Inoue, 1992}

Figs 18, 20

Psychostrophia endoi Inoue 1992: 149, figs 1, 2. [Type locality: Sam Neua (Xam Neua), Laos]; Huang et al. 2019: 44, figs 25-29.

Remarks. The adult and genitalia figures of the holotype from Inoue (1992) have been reproduced for comparison.

Distribution. China (Yunnan, Guizhou, Guangxi Zhuang Autonomous Region), Laos (Xam Neua) (Fig. 25). 


\section{Psychostrophia melanargia Butler, 1877}

Psychostrophia melanargia Butler 1877: 401. [Type locality: Yokohama, Japan]; Leech 1897: 189; Seitz 1912: 278, pl. 48, line f; Minet 2003: 473, fig. 3; Zhu et al. 2004: 224, fig. 156, pl. VI, fig. 3.

Psychostrophia hemimelaena Seitz, 1913 [sic]: Zhu et al. 2004: 225, fig. 157, pl. VI, fig. 4.

Remarks. Zhu et al. (2004) recorded P. melanargia Butler, 1877 and P. hemimelaena Seitz, 1913 (sic), which was originally described as an aberration of $P$. melanargia, viz. P. melanargia ab. hemimelaena Seitz, 1912, from Dailing, Heilongjiang Province and Mt Changbai, Jilin Province, respectively. According to Article 45.6.2 of the Code (ICZN 1999), the name hemimelaena as well as the name catenifer Seitz, 1912, which was also published as a new aberration, are invalid because they are infrasubspecific due to the use of the term "ab." when described. Although these two names were subsequently regarded as $P$. melanargia var. hemimelaena and $P$. melanargia var. catenifera (sic) in the catalogue by Dalla Torre (1924), this action is at most an "elevation in rank" because no description and definition of these taxa can be traced throughout the catalogue. According to Article 45.5.1 of the Code (ICZN 1999), an infrasubspecific name cannot be made available from its original publication by any subsequent action (such as "elevation in rank") except by a ruling of the Commission. Thus, the name $P$. melanargia ab. catenifer Seitz, 1912 is still unavailable. It should also be clarified that the correct spelling of this aberration is catenifer, not catenifera, as indicated in Dalla Torre (1924) and Beccaloni et al. (2003).

The matter of the name P. melanargia ab. hemimelaena is more complicated. As already mentioned above, according to Article 45.5.1 of the Code (ICZN 1999), a name that has infrasubspecific rank under the provisions of this Article cannot be made available from its original publication by any subsequent action (such as "elevation in rank") except by a ruling of the Commission. Article 45.5.1 also states that when a subsequent author applies the same word to a species or subspecies in a manner that makes it an available name (Articles 11-18), even if he or she attributes authorship of the name to the author of its publication as an infrasubspecific name, that subsequent author thereby establishes a new name with its own authorship and date. The name hemimelaena seemed to have been made available under Article 45.5.1 by Zhu et al. (2004) as Psychostrophia hemimelaena Zhu, Wang \& Han, 2004 because they gave a description in Chinese. This would mean that Zhu, Wang and Han 2004 published a new name with its own authorship and date. However, according to Dr Gerardo Lamas (pers. comm.), the actions of Zhu et al. (2004) did not actually comply with Articles 13.1.1, 16.4.1 and 16.4.2 (ICZN 1999). They require every new specific and subspecific name published after 1999, except a new replacement name (a nomen novum), for which the name-bearing type of the nominal taxon it denotes to is fixed automatically (Art. 72.7), must also be accompanied in the original publication by a description or definition that states in words characters that are purported to differentiate the taxon (Article 13.1.1), by the explicit fixation of a holotype, or syntypes, for the 


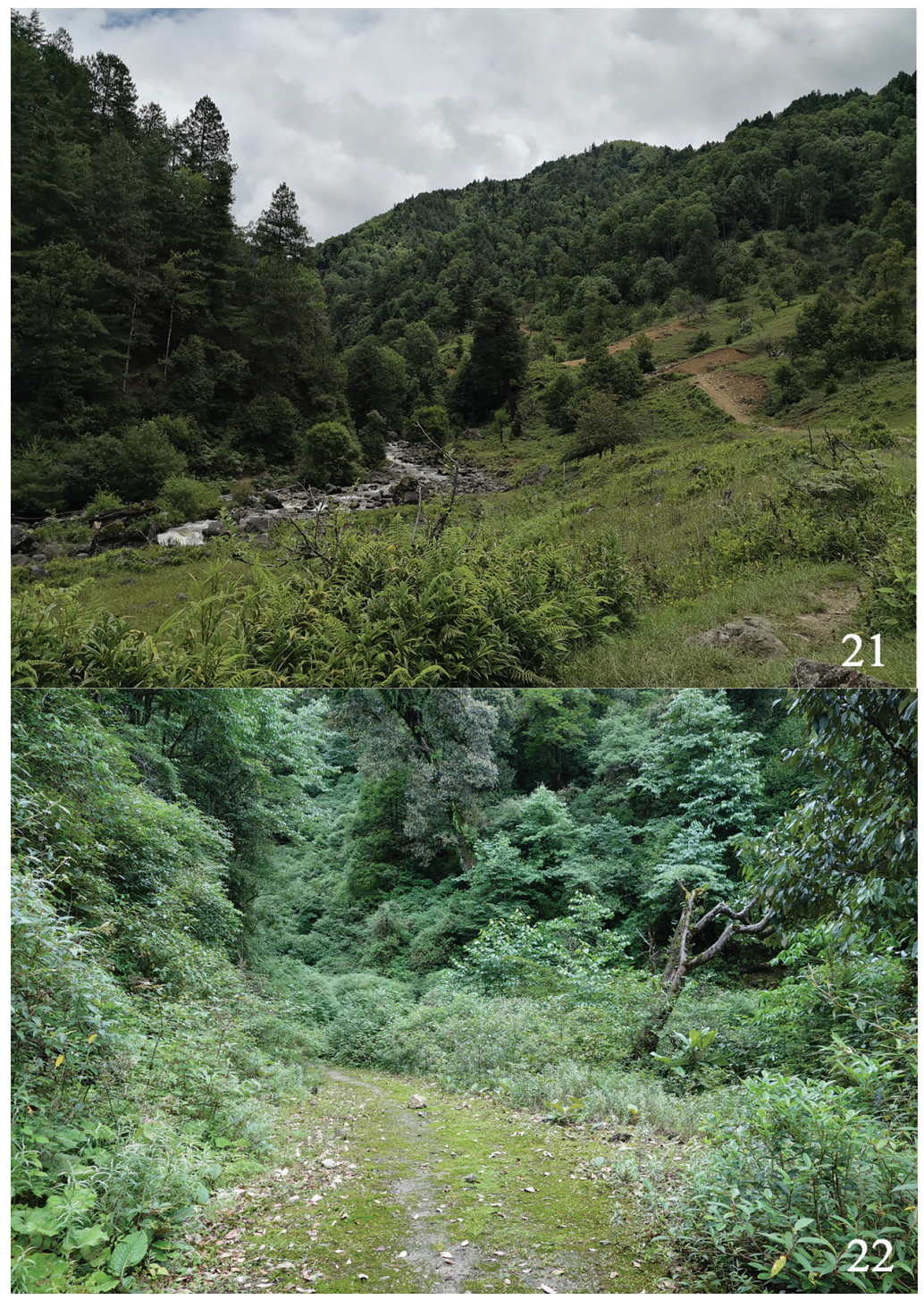

Figures 2I, 22. Habitats of Psychostrophia micronymphidiaria sp.nov. $2 \mathbf{I}$ near Shajiama Bridge, Weixi County 22 Yaojiaping, Lushui County.

nominal taxon (Article 16.4.1) and where the holotype or syntypes are extant specimens, must be a statement of intent that they will be (or are) deposited in a collection and a statement indicating the name and location of that collection (Article 16.4.2). Zhu et al. (2004) did not differentiate hemimelaena from any other taxon in the genus Psychostrophia in their description, fix a holotype for the name hemimelaena, nor state where the "holotype" was because their actions were not deliberate, nor did they intend to make the name hemimelaena available. Thus, the name Psychostrophia melanargia ab. hemimelaena Seitz, 1912 is still unavailable, bearing the original authorship and date. 


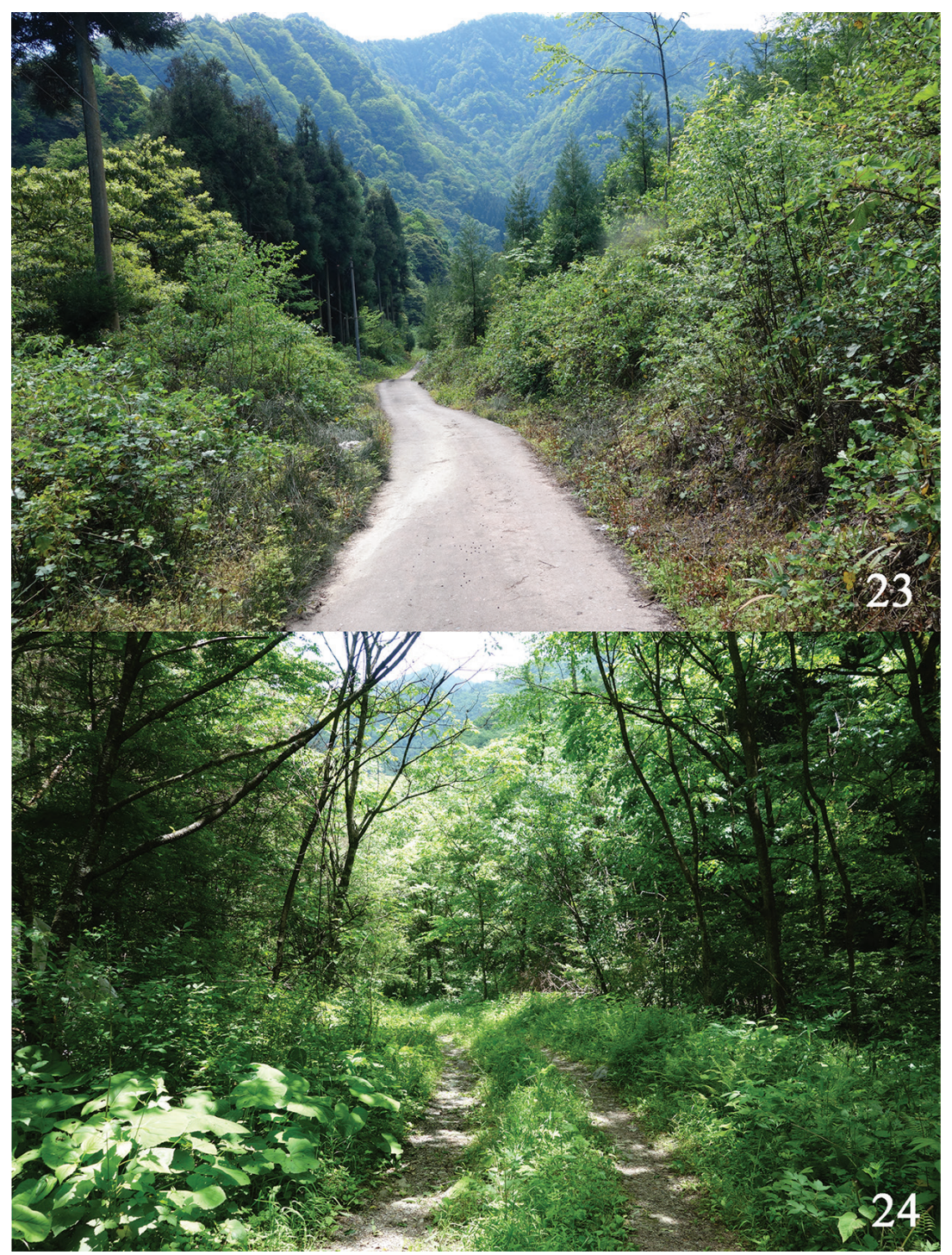

Figures 23, 24. Habitats of Psychostrophia nymphidiaria 23 Mt Niba, Yingjing County 22 Shennongjia, Yichang City.

It is worth noting that the year of publication of $P$. melanargia ab. hemimelaena is 1912, not 1913 as indicated by Dalla Torre (1924), Beccaloni et al. (2003) and Zhu et al. (2004). This name had been published on page 278 in the section on the Uraniidae written by A. Seitz. Although no information on date can be traced throughout the whole section, according to Griffin (1936), the text of the Uraniidae section in the German version of Seitz (1912) was published in Lieferung 99 and received at the British Museum of Natural History on 25.VI.1912. Part 99 encompasses pages 265-344 
and plates 49 and 53. The figure of P. melanargia ab. hemimelaena first appeared on plate 48 published in Lieferung 100, which was received at the British Museum of Natural History on 13.VIII.1912. Part 100 encompasses pages 345-392 and plates 48 and 50. Thus, the publication date of this name must be earlier than 25.VI.1912 and definitely not 1913.

The presence of $P$. melanargia in northeast China is still debatable. Its only known host plant, Clethra barbinervis, the Japanese sweet shrub, is distributed across Japan, Korea, and South and East China. The northernmost distribution record in China is from Mt Lao in the Shandong Province, and this plant is not currently recorded in the flora of northeast China (Qin and Fritsch 2005). Moreover, the specimen figured in Zhu et al. (2004) is not significantly different from the individuals commonly found in Japan, which suggests that the individuals examined by Zhu et al. (2004) were collected from somewhere within the geographic range of $P$. melanargia in Japan and mislabeled as being collected in northeast China. Thus, it is unlikely that the geographic range of $P$. melanargia extends to northeast China, and this species should therefore be excluded from the Chinese fauna. There is a similar case in Lepidoptera regarding the distribution of Neope niphonica Butler, 1881. Takahashi (1996) concluded that an individual of $N$. niphonica labeled as "Kirin, Manchoukuo, 1941-VII-17 (now Jilin Province, PR China)" had been mislabeled, because the host plant genus of this butterfly was not found in northeast China and the wing pattern did not differ from populations found in central Japan.

Distribution. Japan (Honshu, Shikoku, Kyushu) (Fig.25).

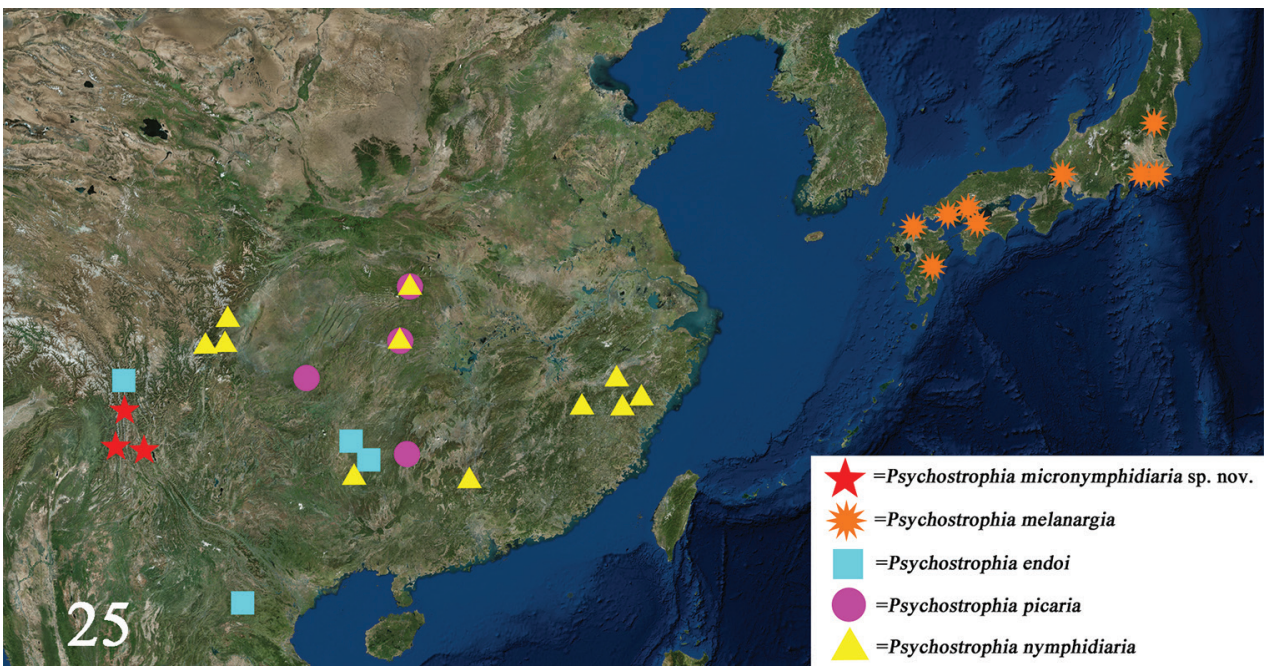

Figure 25. Distribution map of the genus Psychostrophia. Records of distribution are taken from Inoue (1992), Chou and Yuan (2001), Owada (2011), Huang et al. (2019), An Identification Guide of Japanese Moths Compiled by Everyone http://www.jpmoth.org, Shiiba Research Forest, Kyushu University http:// www.forest.kyushu-u.ac.jp/miyazaki/index.php, and the present study. 


\section{Key to the genus Psychostrophia Butler, 1877}

1 Forewing from base to medial zone with two yellow or whitish areas, the basal one situated along discal cell, the outer one extending from costal region to postmedial region

Psychostrophia melanargia

- $\quad$ Forewing from base to medial zone with only one pale white or whitish area ....2

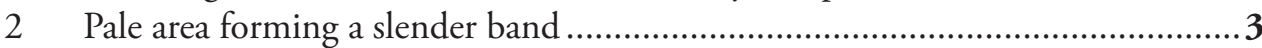

- Pale area forming a trapezoidal or triangular zone .............................................4

3 Hindwing postmedial series comprised of a single transverse band

- Hindwing postmedial series comprised of several separated dots

Psychostrophia picaria

Psychostrophia endoi

4 Forewing discal cell bar slender .....Psychostrophia micronymphidiaria sp. nov.

- Forewing discal cell bar short and robust. Psychostrophia nymphidiaria

\section{Acknowledgements}

We express our sincere thanks to Dr Xiangqun Yuan for permission for using the photos of the true holotype of Stiboges lushanica and another "holotype" of this taxon, to Dr Mamoru Owada (Tsukuba, Japan) for providing valuable literature on Psychostrophia endoi, to Mr Hao Huang (Qingdao, Shandong, PR China), Dr Liu-sheng Chen (Guangdong Academy of Forestry, Guangzhou, PR China), Dr Guo-xi Xue (Zhengzhou, Henan, PR China), Dr Hou-shuai Wang (SCAU, Guangzhou, PR China), Mr Qi-tong Huang (Northwest Agricultural and Forestry University, Yangling, PR China), Dr Hai-ling Zhuang (Shenzhen, Guangdong, PR China), Ms Jing Tang (Nanjing Normal University, Nanjing, PR China), Mr Zhi-peng Miao, Ms Lan-lan Huang, Mr Yang Long, Mr Zhen Li, Ms Wan Lu (SCAU, Guangzhou, PR China), and Mr Yu-fei Li (Xi'an, PR China) for collecting valuable materials and providing useful information and photographs. We are also grateful to Mr Sun-bin Huang, Ms Meng-zhen Chen and Ms Zi-jun Ma (SCAU, Guangzhou, PR China) for helping us with genitalia photographs. Special thanks are due to Dr Gerardo Lamas (Universidad Nacional Mayor de San Marcos, Lima, Peru) and Dr Hao Xu (Mianyang Teachers' College, Mianyang, PR China) for critical advises on nomenclature problem on Psychostrophia melanargia ab. hemimelaena. We are also grateful to Editage (www.editage.cn) for English language editing.

\section{References}

Beccaloni G, Scoble M, Kitching I, Simonsen T, Robinson G, Pitkin B, Hine A, Lyal C (2003) The Global Lepidoptera Names Index (LepIndex). https://www.nhm.ac.uk/our-science/ data/lepindex/lepindex [Accessed on: 2019-12-2] 
Butler AG (1877) Descriptions of new species of Heterocera from Japan.-Part I. Sphinges and Bombyces. The Annals and Magazine of Natural History (Series 4) 20: 393-404. https:// doi.org/10.1080/00222937708682255

ButlerAG(1881) Onacollection ofbutterfliesfrom Nikko, centralJapan. The Annalsand Magazine of Natural History (Series 5) 7: 132-140. https://doi.org/10.1080/00222938109459486

Callaghan CJ (2009) The riodinid butterflies of Vietnam (Lepidoptera). Journal of the Lepidopterists' Society 63(2): 61-82.

Chou I, Yuan XQ (2001) New species, new subspecies and new record of butterflies (Lepidoptera) from China (IV). Entomotaxonomia 23(2): 141-146.

Dalla Torre KW von (1924) Epiplemidae. In: Strand E (Ed.) Lepidopterorum catalogus 30: 1-38. https://doi.org/10.5962/bhl.title.82093

Fruhstorfer H (1914) Tribus: Nemeobiidi. In: Seitz A (Ed.) The Macrolepidoptera of the World Volume 9, the Rhopalocera of the Indo-Australian Faunal Region. Alfred Kernen, Stuttgart, 772-798. https://doi.org/10.5962/bhl.title.149701

Griffin FJ (1936) The contents of the parts and the dates of appearance of Seitz' Grossschmetterlinge der Erde (The Macrolepidoptera of the world), Lieferungen 1 to 130 Palaearctic and 1 to 575 Exotic. Vols. 1 to 16, 1907-1935. Transactions of the Royal Entomological Society of London 85(10): 243-279. https://doi.org/10.1111/j.1365-2311.1936.tb00232.x

Huang SY, Wang M, Da W, Fan XL (2019) New discoveries of the family Epicopeiidae from China, with description of a new species (Lepidoptera, Epicopeiidae). ZooKeys 822: 3351. https://doi.org/10.3897/zookeys.822.32341

ICZN (1999) International Code of Zoological Nomenclature.4(th Edn.). International Trust for Zoological Nomenclature, The Natural History Museum, London, 306 pp.

Inoue H (1982) Epiplemidae. In: Inoue H, Sugi S, Kuroko H, Moriuti S, Kawabe A, Owada M (Eds) Moths of Japan (Vol. 1). Kodansha, Tokyo, 575-579.

Inoue H (1992) A new species of Psychostrophia Butler from Laos (Epiplemidae). Tyo to Ga 43(2): 149-150.

Jpmoth: An Identification Guide of Japanese Moths Compiled by Everyone (2019) Jpmoth: An Identification Guide of Japanese Moths Compiled by Everyone. http://www.jpmoth. org [Accessed on: 2019-Dec.-2]

Kishida Y (2006) ガをチョウと間違えることってあるの? [Is it possible to misidentify a moth as a butterfly?] Yadoriga 208: 1-42. [in Japanese]

Klots AB (1970) Lepidoptera. In: Tuxen SL (Ed.) Taxonomist’s Glossary of Genitalia in Insects. Second Revised and Enlarged Edition. Munksgaard, Copenhagen, 115-130.

Leech JH (1897) On Lepidoptera Heterocera from China, Japan, and Corea. The Annals and Magazine of Natural History (Series 6) 19: 180-235, 297-349, 414-462, 543-573, 640679. [pls 6, 7] https://doi.org/10.1080/00222939708680542

Minet J (2003) The Epicopeiidae: phylogeny and a redefinition, with the description of new taxa (Lepidoptera: Drepanoidea). Annales de la Société entomologique de France (NS) 38(4): 463-487. https://doi.org/10.1080/00379271.2002.10697355

Oberthür C (1893) Lépidoptères d'Asie. Études d'entomologie 18: 11-45. [pls 2-6] https:// doi.org/10.5962/bhl.title.9398

Owada M (2011) Epicopeiidae. In: Kishida Y (Ed.) The Standard of Moths in Japan 2. Gakken Education Publishing, Tokyo, 126-127. 
Qin HN, Fritsch P (2005) Clethraceae. In: Wu ZY, Raven PH, Hong DY (Eds) Flora of China 14. Science Press, Beijing and Missouri Botanical Garden Press, St Louis, 238-241.

Seitz A (1912) Family Uraniidae. In: Seitz A (Ed.) The Macrolepidoptera of the World Volume 2, the Palearctic Bombyces \& Sphinges. Alfred Kernen, Stuttgart, 275-280. https://doi. org/10.5962/bhl.title.61923

Shiiba Research Forest, Kyushu University (2019) Shiiba Research Forest, Kyushu University. http://www.forest.kyushu-u.ac.jp/miyazaki/index.php [Accessed on: 2019-Dec.-2]

Takahashi M (1996) On the specimen of Neope niphonica Butler (Lepidoptera, Satyridae) labeled to be collected in the Northeastern District of China. Transactions of the Lepidopterological Society of Japan 47(2): 106-107.

Zhu HF, Wang LY, Han HX (2004) Lepidoptera. Hepialidae. Epiplemidae. Fauna Sinica (Insecta) (Vol. 38). Science Press, Beijing, 291 pp. 